\title{
EDITORIAL
}

\section{ALISON LEE}

This issue of Literacy and Numeracy Studies takes up two major themes shaping the landscape of research and practice in adult literacy. The first of these is the more recent of the two: the intersections between literacy and professional and workplace practice. The second is perhaps a more sustained and enduring concern in the field with the relationship of literacy to context, place and culture. In this sense, this issue of the journal is an expression of the reach and diversity of concerns with literacy in 'social participation, the utilisation of social resources and the quality of life' (Green, Lo Bianco and Wyn, this volume) and carries forward critical debates for the field across the span of practice from the workplace, to the classroom to the community.

Linking these apparently disparate domains is a preoccupation with the imperative for literacy in relation to contemporary social life, and a call for appropriate forms of theorising of the meanings of literacy in different settings and circumstances. Whether this finds expression in the increasing 'textualisation' of work; the increasing 'individualisation' and 'responsibilisation' of populations in relation to their own health; the 'commodification' of basic literacy work in remote Aboriginal communities, or the move in literacy research towards trans-national studies of modes of collaborative pedagogy - all of these acknowledge the socio-political significance as well as the complexity and challenge of literacy.

The first two articles are strongly oriented to the increasing reach of literacy into professional and workplace worlds and the contemporary lifeworld of social particpation. A key theme here is the intensification of the relationship between literacy and the conduct of contemporary social life - in work, in professional 
practice, in health and the relationship of individuals to institutions and systems of governance. The first article, by Scheeres, focuses in the increasing textualisation of the workplace. She documents the ways in which increasing demands for literate practices in relation to writing and reading, but also for talk - in meetings and teamwork etc - are serving to shape work in quite different ways. Changing work requires and produces new kinds of workers, whose worker identities are more and more tied up with being literate in increasingly complex ways. The 'scene of work' has indeed, as Rob McCormack said a decade and a half ago, become the 'scene of discourse' (McCormack 1991).

The 'scene of discourse' is also the theme of the article by Green, Lo Bianco and Wyn on the intersections between literacy and health. Titled 'Discourses in Interaction', the article argues the need for the importance of a properly theorised take on the intersection of these fields, focusing on the 'sub-field' of 'health literacy'. The convergence of education and health at the site of health literacy construct and enact participation in health in ways that require theorisation from a cross-sectoral perspective, in order to make explicit what is often implicit between the two fields: on the one hand, through contemporary systems of governance, an increasing emphasis on individual responsibility for health and wellbeing and, on the other, a long tradition in adult literacy of socio-cultural models emphasising social participation and community.

The third and fourth articles continue a theme of participation and community, albeit in contrasting ways. Both invoke a focus on place and, in different ways, on cultural difference. Melodie Bat's account of the struggle for literacy in a Central Australian Aboriginal community tells of circumstances that may shock many readers. So often the story of access to literacy for Aboriginal people is told as a story of disadvantage. Here, in this beautifully narrated story, we see laid out a 
different kind of account, where what is taken for granted in urban settings - access to basic literacy materials - is dependent on profit margins at the local store. This extreme expression of the application of a market logic by governments to manage complex social responsibilities is deeply shocking to those of us who want to see literacy as a human right. This is an important corrective to otherwise taken-for-granted stories of literacy and an important counterpoint to the metro-centrism of much adult literacy research, even that purporting to be 'critical'.

Finally, in the article by Taylor, Evans and Abasi, we see the emergence of cross-national research on adult literacy, drawing our attention to the cultural and pedagogical similarities, as well as the striking differences, between what appear to be parallel systems. Canada and the UK have certain cultural traditions in common but significant differences. The article presents an argument for, and a useful documentation of, collaborative approaches to adult literacy pedagogy. While it presents itself as socially oriented, it continues at times to work off cognitivist frames for learning, seeing learning as an individual achievement. In this sense, the article demonstrates a continuing need for theoretical work across the boundaries of national research communities and research paradigms. A major challenge for the research field is to build an international conversation and to engage in cross-nation research studies that build the capacity to better engage in the increasing complexity of the literacy/social participation relation.

\section{References}

McCormack, Rob (1991) Framing the Field: Adult Literacies and the Future, in Christie, $F$, (ed) Teaching Critical Social Literacy, Report of the Project of National Significance in the Pre-service Preparation for Teachers of English Literacy, 
Canberra, Department of Employment, Education and Training, pp 224-256. 